\title{
How to Select and Order NAPP and NHAP Photographs
}

The locations of aerial photographs from the National Aerial Photography Program (NAPP) and the National High Altitude Photography (NHAP) program are shown on flight-line indexes, which are available on microfiche or printed copy of microfiche.

Flight-line indexes are maps on which the centers of aerial photographs are represented as dots and identified by roll and frame numbers and other information. By circling your area of interest using such information as towns, roads, and names, you can see which photographs cover that area.

Figure 1 represents flight-line information as it appears on flight-line indexes. The center of each photograph is shown by a dot. At least two dots in each north-south flight line are identified by roll and frame number (that is, 210-129). Roll and frame numbers for unnumbered dots are determined by counting up or down. Some dots may show two roll and frame numbers to indicate an overlap area between two rolls of film. In this case, either roll can be used. The absence of dots along individual flight lines indicates that photographs meeting program standards are not available.

An outline showing the approximate area covered by one photograph is drawn around at least one dot in each flight line. By tracing this outline and centering it on the dots that fall within or next to your area of interest, you can select the specific exposures you need by roll and frame numbers.

Additional information required for ordering is in the project description block located in the margin of each flight-line index map.

Figure 2 represents an order done by using information from figure 1 . The photograph data and project identification number are taken from the project description block. Roll and frame numbers are determined by finding the coverage outlines that are drawn around the dots closest to the area of interest. Product codes and prices for photographic products and enlargements are shown on the enclosed price list.

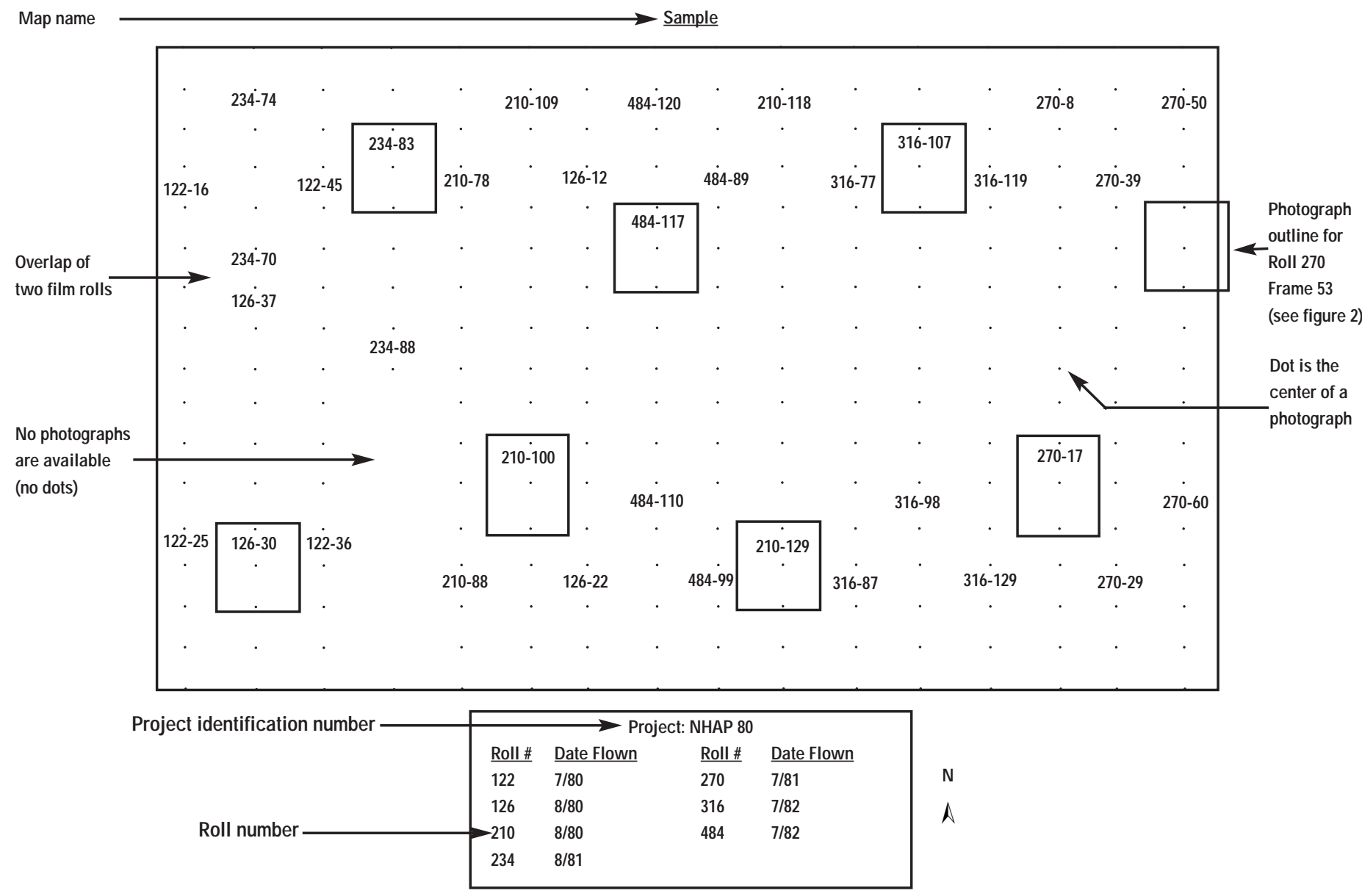

Figure 1. Diagram of a map showing film coverage. 


\begin{tabular}{|c|c|c|c|c|c|c|c|c|c|c|c|c|}
\hline $\begin{array}{l}\text { Project ID } \\
\text { Number }\end{array}$ & Roll No. & $\begin{array}{l}\text { First } \\
\text { Frame }\end{array}$ & $\begin{array}{l}\text { Last } \\
\text { Frame }\end{array}$ & $\begin{array}{l}\text { Prod. } \\
\text { Code }\end{array}$ & $\begin{array}{l}\text { No. of } \\
\text { Frames } \\
\end{array}$ & $x$ & $\begin{array}{l}\text { No. Copies } \\
\text { Each Frame } \\
\end{array}$ & Qty. & $x$ & $\begin{array}{l}\text { Unit } \\
\text { Price } \\
\end{array}$ & $=$ & $\begin{array}{l}\text { Total } \\
\text { Price } \\
\end{array}$ \\
\hline NHAP 80 & 126 & 30 & 30 & 63 & 1 & & 1 & 1 & & 16.00 & & 16.00 \\
\hline NHAP 80 & 234 & 83 & 85 & 24 & 3 & & 2 & 6 & & 18.00 & & 108.00 \\
\hline NHAP 80 & 210 & 129 & 129 & 03 & 1 & & 1 & 1 & & 10.00 & & 10.00 \\
\hline NHAP 80 & 270 & 16 & 18 & 26 & 3 & & 1 & 3 & & 33.00 & & 99.00 \\
\hline
\end{tabular}

Figure 2. Example of completed order form entries using sample index.

\section{NAPP Aerial Photography}

The NAPP began in 1987 and continues to the present day, and thus it usually represents the most recent USGS photographs available. Each of the conterminous 48 states is photographed every 5 to 7 years. You can match the roll number with the date of the photograph by referring to the project description box (fig. 3, number 3). NAPP photographs cover 32.3 square miles. Blackand-white and/or color-infrared products are available. The paragraphs shown below explain how to derive the correct Project ID Number:

- If color infrared is the film type indicated on the index, and color-infrared prints or positives are desired, the Project ID Number is NAPP. Note that color-infrared negatives are not available.

- If black-and-white is the film type indicated on the index, and black-andwhite prints, positives, or negatives are desired, the Project ID Number is NAPPW.

- If color infrared is the film type indicated on the index, but black-and-white prints are desired, the Project ID Number is NAPPB. Please note this is only offered for NAPP roll numbers below 9600.

- If color infrared is the film type indicated on the index, but black-and-white negatives are desired, the Project ID Number is NAPP, the Product Code is F103, and the cost is $\$ 10$.

- A few black-and-white indexes indicate NAPPA as the project. When this occurs, use NAPPA as the Project ID Number.

\section{NHAP Aerial Photography}

The NHAP covers the conterminous United States from 1980 to 1989 . Each black-andwhite frame covers approximately 130 square miles, and color-infrared frames cover approximately 70 square miles. When ordering NHAP photographs, you must include the Project ID Number. This number is located directly above the roll number and the date (fig. 4, number 3). Black-and-white prints derived from color-infrared sources are

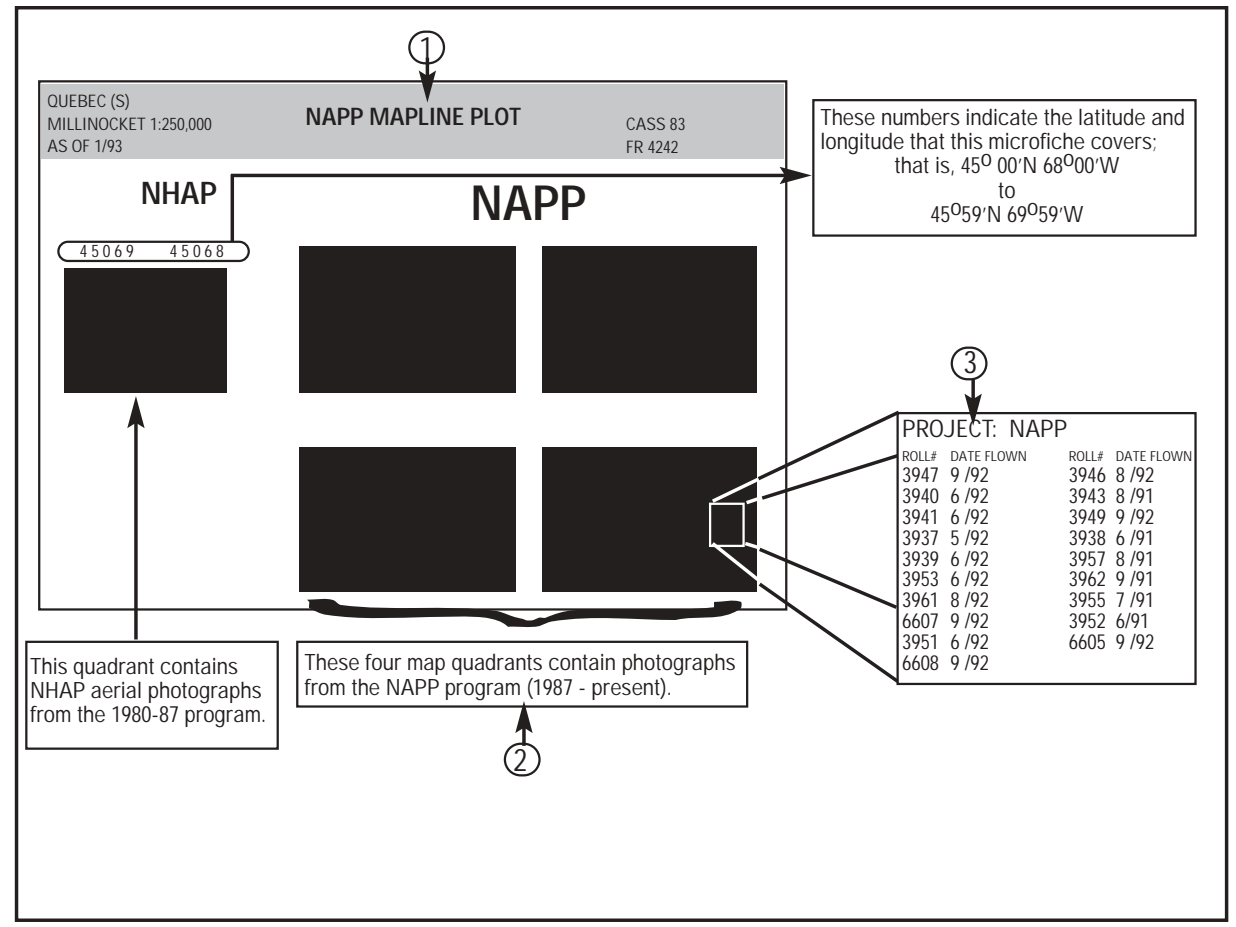

Figure 3. Example of NAPP microfiche

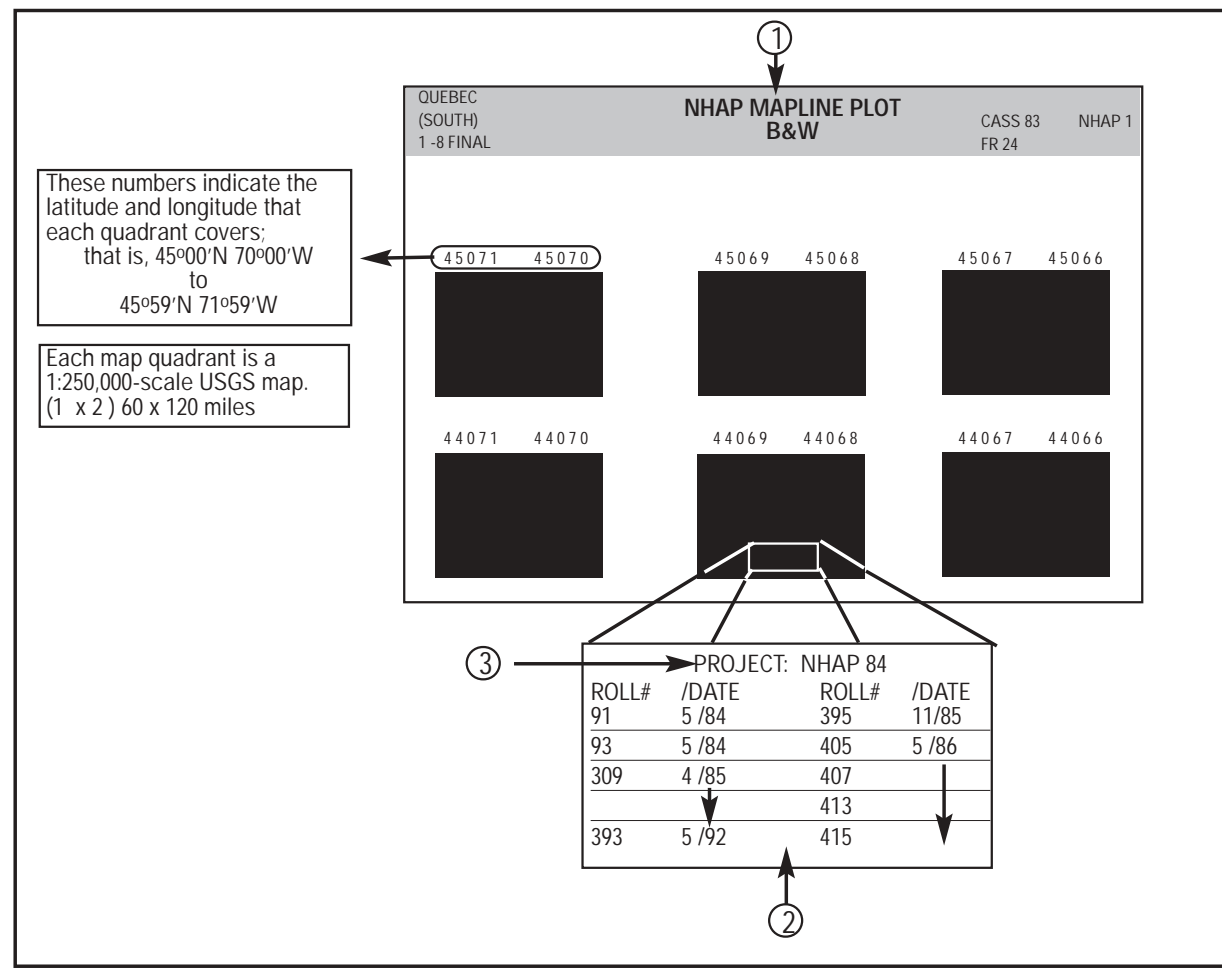

Figure 4. Example of NHAP microfiche 
not offered for the NHAP program.

Customers can, however, order black-andwhite negatives derived from NHAP colorinfrared sources by providing the correct NHAP Project ID Number, indicating Product Code 103, and paying \$10 per negative.

\section{Delivery Schedule}

Photographic products are normally shipped within 4 to 6 weeks of order receipt. You can order products on a priority basis by paying three times the normal cost (the \$5 handling charge is unchanged). Priority deliveries are made in 5 to 7 working days by private courier; the courier must have a street address for delivery (no P.O. Box numbers or drawer numbers).

\section{Contact Information}

These orders are processed at the EROS Data Center. If you want to contact them directly, please call:

\section{U.S. Geological Survey \\ EROS Data Center \\ Sioux Falls, SD 57198-0001 \\ 605-594-6151 VOICE \\ 605-594-6589 FAX \\ 605-594-6933 TDD}

Examples of photographs photo examples and more information about the NAPP and NHAP programs can be accessed online at ask.usgs.gov/photos.html.

\section{Ordering Information}

For prices of aerial photographs, visit the pricing information Web site at mapping.usgs.gov/esic/prices/ aerial_photos.html.

The aerial photographs order form can be found at mac.usgs.gov/mac/isb/pubs/forms/ aerialphotos.html.

NAPP and NHAP photographs can also be ordered using Earth Explorer and Photofinder at earthexplorer.usgs.gov.

\section{Information}

For information on these and other USGS products and services, call 1-888-ASK-USGS, use the Ask.USGS fax service, which is available 24 hours a day at 703-648-4888, or visit the general interest publications Web site on mapping, geography, and related topics at mac.usgs.gov/mac/isb/ pubs/pubslists/.

For additional information, visit the ask.usgs.gov Web site or the USGS home page at www.usgs.gov. 